Dunlavy $S$. Two siblings with recurrent cardiorespiratory arrest: Munchausen syndrome by proxy or child abuse? Pediatrics 1983;71:715-20

4 Meadow R. Suffocation. Br Med f 1989;298:1572-3. (10 June.)

SIR,--Your recent articles and correspondence ${ }^{1+4}$ prompt me to take up two points raised by Professor Roy Meadow.

Our current findings confirm completely our previous estimates of the likely prevalence of filicide (eight out of 115 in our last series). The problem now is not its existence but of doing something about it in prevention. But filicide is only one of a number of facets which come under the heading of cot deaths. The diagnosis sudden infant death syndrome was barely justifiable in the first place; has not been proved to be beneficial, certainly towards elucidating the causes of death of children; and is probably harmful in our attempts to prevent some of these deaths.

During the past 20 years we have seen a series of hypotheses as "the theory of the month," some of them nonsensical, but others almost certainly applying to a small proportion of such deaths. When any such hypothesis is applied to the total group of deaths, however, answers come out negative. The result has been that vast sums of money have been spent on research that has largely been almost negative. Any hypothesis for unexpected death that is related not to some obscure reflex or chemical but to some aspect of parental care is seen as a threat to all of the parents, and paediatricians and others who have taken on the emotional care of the parents feel called on to defend them. There are probably at least half a dozen distinct entities in what is labelled sudden infant death syndrome.

The time is fast arriving when this "dustbin" approach to diagnosis must be abandoned so that the causes of death in children who die unexpectedly can be investigated outside the light of media publicity and without distressing innocent parents unnecessarily. The $B M F$ has taken some leads in medical publication; could it not start by referring to unexpected infant deaths rather than the sudden infant death syndrome?

JOHN L EMERY

Department of Paediatrics.

University of Sheffield

Sheffield S10 3BN

Tallon DS. Suffocation and sudden infant death syndrome. BrMed f 1989;299:178. (15 July

2 Southall DP, Sam!lels MP, Stebbens VA. Suffocation and sudden infant death syndrome. Br. Hed f 1989;299:178. 15 July:

3 Hilton JIIN. Suffeation and sudden infant death syndrome. Br.11:d f 1989;299:178-9. (15 July.

4 Meadow R. Suffocation and sudden infant death syndrome. Br.11:d 9 1989:299:179. i 15 Juls.

5 Meadow R. Suffocation. Br.Hed $f$ 1989:298:1572-3. (10 June.)

SIR,-Our findings on suffocatory abuse were based on all the two generation abusive families ascertained in our health district. ${ }^{1}$ The death rate for young children in these families was more than four times the rate for families in social class $\mathrm{V}$, and the sibs had an even higher death rate than the index children. There were 39 child victims of suffocatory abuse, with mothers responsible for all but three of the 58 instances.

Mr D S Tallon is incredulous that mothers can behave like this, on the grounds that child abuse is "mainly the responsibility of men." West European, North American, and Australian reports indicate that within the home battering of babies and severe repetitive physical abuse of young children are usually done by both parents (where there are two), and most papers incriminate biological mothers in small excess over fathers and male cohabitees together.

Suffocatory abuse, poisonings, mental handicap induced by violence, Munchausen's syndrome by proxy, and killings of very young children are predominantly the responsibility of (a few) biological mothers. Anyone who has sat in 100 child protection case conferences knows that this is not reflected in criminal statistics. Admissions by mothers responsible for killings, suffocatory abuse, semisecret violent shakings, and mental handicap induced by violence, and confirmations by relatives, were usually revealed late or in ways which would not have been open to the sort of legal proof that Dr J M N Hilton requires.: There was often a downward spiral of stresses, with probable synergistic interactions between these adversities. Many assaults were nocturnal, confused, the child already crying excessively, frequently with cold, bronchitis, or other stress. Shaking in frustrated fury or desperation sometimes had caused some inhalation of vomit. Nevertheless, there were three cases of mothers having been observed by grandmothers intentionally holding the baby so that it would inhale its own vomit.

Why not reverse the emphasis as follows? Ninety per cent of sudden infant deaths are innocent, the consequence of various medical causes; $8 \%$ are a complex mixture of unknown biological causes, mismanagement, or episodes of secret abuse; and $2 \%$ are deeply suspicious or the parent is known to be culpable.

JACK OLIVER

Burderop Hospital,

Wroughton,

Swindon SN4 0QA

1 Oliver JE. Successive generations of child maltreatment: the children. Br f Psychiatry 1988;153:543-53.

Tallon DS. Suffocation and sudden infant death syndrome. Br.Med F 1989;299:178. (15 July.)

3 Hilton JMN. Suffocation and sudden infant death syndrome. Br Med f 1989;299:178-9. (15 July.)

SIR, - Professor Roy Meadow's article on smothering in cot deaths ${ }^{1}$ and the response it has evoked illustrate how debates recur in cycles. Much of the difficulty relates to imprecision in terminology and a lack of logic in argument.

We cannot talk about "the cause" of cot death while concurrently holding to a multifactorial theory. The possible role of asphyxia is at the heart of the problem, whichever hypothesis is held. Thus a publication for general readers maintains that "it is essential to defeat the remarkably persistent rumour that mechanical suffocation has anything to do with SIDS [sudden infant death syndrome]." 2 The rumour persists, despite the conventional wisdom that findings at necropsy such as petechial haemorrhages and aspiration of gastric contents are epiphenomena and that sleeping position, mattresses, bedclothes, etc, are irrelevant. This is comparable with maintaining that because giant cell granulomas are found in several unrelated conditions their presence cannot indicate tuberculosis.

It may well be that an unwillingness to recognise the possibility of mechanical asphyxia has itself exaggerated the attribution of the possible role of deliberate smothering. Certainly, we should use terms such as smothering, asphyxia, and anoxia more precisely. In 30 years' experience of cot deaths I found presumptive evidence of asphyxia in about half the cases (in no case was deliberate suffocation established). This does not compare with the results of the multicentre study of neonatal mortality and the publicity of the Foundation for the Study of Infant Deaths, ${ }^{34}$ in which the certified causes of death are grouped into general disease categories or unknown causes.

The correspondence of 15 July is a rerun of that of 8 April, which followed the editorial of 18 March, with the exception that the question of maternal smothering has been introduced. The earlier letters - for example, those by Professor D F W Harrison and Dr $\mathrm{H}$ Barrie $^{6}$-emphasise the "precarious limitations of airflow present in children" and the readiness with which children regurgitate, whether awake or asleep. We have been told for many years that babies must be put to sleep prone, but the Hong Kong and Dutch reports " at the very least call into question the validity of this dogma. Is it not ironic that while a welter of abstruse chemical and immunological mechanisms are invoked and studied we may not really know how babies should be nursed?

Professor Meadow wishes that the term "sudden infant death syndrome" could be abolished. I entirely agree with his contention because many pathologists were carried along with this convention when failure to comply with it could be regarded as insensitivity or adding to parental distress. Thus it transpired that if a simple factor such as mechanical obstruction were found this, by definition, could not be the cause of death because it had already been decreed that small babies just do not choke on their vomit or smother in their beds. There is no such prohibition when hitherto healthy adults or psychiatric patients die from aspiration. I have resorted to the label of sudden infant death syndrome when, for example, the evidence strongly suggested hyperpyrexia with its connotation of parental error.

Finally, I suggest that there are more unexplained deaths in adults (despite full postmortem examination) each year than there are in children under 2 years of age.

Princess of Wales Hospital,

D E B POWELI

Bridgend CF31 IRQ

1 Meadow R. Suffocation Br Med f 1989;298:1572-3. (10 June.)

2 Knight B. Sudden death in infancy. London: Faber and Faber, 1983:45.

3 Knowelden J, Keeling J, Nicholl JP. A multicentre study of postneonatal mortality. Sheffield: Medical Care Research Unir. University of Sheffield, 1984

4 Limerick S. Report of the multicentre study of postneonatal mortality. London: Foundation for the Study of Infant Deaths, 1985.

5 Harrison DFN. Sudden infant death syndrome. Br Med $\mathcal{J}$ 1989;298:959

6 Barrie H. Sudden infant death syndrome. Br Med 7 1989;298 959

7 Lee NNY, Chan YF, Davies DP, Law E, Yip DCP. Sudden infant death syndrome in Hong Kong: confirmation of low incidence. Br Med f 1989;298:721.

8 De Jong GA, Engelberts AC, Koomen-Liefting AJMI, Kostense PJ. Cot death and prone sleeping position in The Netherlands. Br.Med F 1989;298:722.

\section{Captopril and hypertension in black diabetics}

SIR,-Drs H H Parving and E Hommel used captopril to treat hypertension associated with diabetic nephropathy in some of their patients. It is important to recognise possible ethnic differences in therapeutic response to captopril The data sheet that accompanies enalapril maleate (Innovace) indicates that there may be a reduced therapeutic response in black patients if the drug is used as the sole treatment for hypertension. No such precaution is presented in the data sheets accompanying any of the captopril products (Captopen, Capozide, Acepril, and Acezide). This is an unfortunate omission; like enalapril, low dose captopril may be less effective when used as the sole antihypertensive agent in black patients. ${ }^{2}$ In such patients, however, the lowered response to either angiotensin converting enzyme inhibitor can usually be abolished by including a thiazide diuretic in the therapeutic regimen.

The potentially reduced efficacy of low dose captopril in some black patients is of some importance in view of the fairly high incidence of hypertension associated with diabetes mellitus in the West Indian population of cities such as Birmingham and Wolverhampton. " Captopril is of benefit in diabetic nephropathy and does not greatly alter the blood glucose profile. These factors taken together with the lack of any indication in the data sheets to suggest that captopril may be less efficacious in black patients may lead to the notion that the drug would be a useful alternative 